\title{
Kelvin waves in stratosphere, mesosphere and lower thermosphere temperatures as observed by TIMED/SABER during 2002-2006
}

\author{
Jeffrey M. Forbes ${ }^{1}$, Xiaoli Zhang ${ }^{1}$, Scott E. Palo ${ }^{1}$, James Russell ${ }^{2}$, Christopher J. Mertens ${ }^{3}$, and Martin Mlynczak ${ }^{3}$ \\ ${ }^{1}$ Department of Aerospace Engineering Sciences, UCB 429, University of Colorado, Boulder, CO 80309-0429 \\ ${ }^{2}$ Center for Atmospheric Sciences, Hampton University, Hampton, VA 23668 \\ ${ }^{3}$ NASA Langley Research Center, Hampton, VA 23681-0001
}

(Received September 28, 2007; Revised March 18, 2008; Accepted March 25, 2008; Online published May 14, 2009)

\begin{abstract}
Temperature measurements from the SABER instrument on the TIMED spacecraft are used to elucidate the properties of Kelvin waves and other equatorial oscillations over the altitude range 20-120 km during 2002-2006. The dominant Kelvin waves transition from long periods (5-10 days) and short wavelengths (9-13 km) in the stratosphere, to shorter periods (2-3 days) and longer wavelengths $(35-45 \mathrm{~km})$ in the $80-120 \mathrm{~km}$ height region. Ultra-Fast Kelvin Waves (UFKW) with periods of 2.5-4.5 days intermittently exist at amplitudes of order 3-10 K between $80-120 \mathrm{~km}$ during all months of the year, with variability at periods typically in the 20-60 day range. An Intra-seasonal oscillation (ISO) of zonal mean temperatures also exists with periods 20-60 days that may be driven by Eliassen-Palm Flux Divergences (EPFD) due, at least in part, to UFKW and migrating diurnal tides. Key words: SABER (Sounding the Atmosphere using Broadband Emissioni Radiometry), TIMED (Thermosphere Ionosphere Mesosphere Energetics Dynamics), Ultra-Fast Kelvin Waves (UFKW), Intra-seasonal oscillation (ISO), Eliassen-Palm Flux Divergences (EPFD).
\end{abstract}

\section{Introduction}

Kelvin waves are equatorially-trapped oscillations excited by tropical convective processes. Kelvin waves in the lower stratosphere commonly occur with periods of order 10-20 days and are known as "slow" Kelvin waves or "Wallace-Kousky" waves (Wallace and Kousky, 1968; Maruyama, 1968). The so-called "fast" waves with periods of 6-10 days in the stratosphere (Hirota, 1979) and the 3-6-day period "ultra-fast" waves in the stratospheremesosphere are now well-established (Salby et al., 1984; Canziani et al., 1995; Lieberman and Riggin, 1997). Due to their longer vertical wavelengths $(>20 \mathrm{~km})$ and shorter periods (and hence reduced susceptibility to dissipation), only the ultra-fast Kelvin waves (UFKW) are thought to be capable of propagating to the mesopause (ca. $95 \mathrm{~km}$ ) and perhaps even into the overlying thermosphere. The UFKW have been observed in the mesosphere and lower thermosphere (MLT, 50-100 km) by instruments in space (Canziani et al., 1995; Lieberman and Riggin, 1997) and on the ground (Riggin et al., 1997; Yoshida et al., 1999; Vincent, 1993).

Many of the previous observations of UFKW are either restricted in altitude, and/or cover relatively short periods of time. However, the SABER instrument on the TIMED satellite, launched December 21, 2001, has made nearcontinuous measurements between $20-120 \mathrm{~km}$ and $-50^{\circ}$ to $+50^{\circ}$ latitude, extending from 2002 to 2006 . Thus, these data have the potential to provide a new and illuminating

Copyright (c) The Society of Geomagnetism and Earth, Planetary and Space Sciences (SGEPSS); The Seismological Society of Japan; The Volcanological Society of Japan; The Geodetic Society of Japan; The Japanese Society for Planetary Sciences; TERRAPUB perspective on Kelvin waves and other equatorial waves in the middle and upper atmosphere, and in particular, the evolution of the wave spectrum from the stratosphere to the lower thermosphere. The purpose of this paper is to provide this perspective. A detailed study of the diurnal and semidiurnal tidal spectra, and their seasonal-latitudinal and inter-annual evolutions in the stratosphere, mesosphere and lower thermosphere will be reported on in forthcoming papers.

\section{Data and Processing Methods}

The SABER temperature measurements analyzed here cover from day 25 of 2002 to day 365 of 2006 with some occasional missing days. Since we consider data equatorward of $\pm 50^{\circ}$ latitude where sampling is unaffected by yaw maneuvers, and relatively few data gaps exist, we have almost continuous (but asynoptic) coverage in UT and longitude. We process the data using consecutive 60-day windows moving forward in time once per day. Due to the precession rate of the TIMED satellite and the dual-node sampling of the SABER instrument, a 24-hour local time cycle (except for a few hours near noon) is covered in each 60day window. Due to Earth's rotation and the $\sim 90$-minute period of TIMED's orbit, about 15 longitudes are sampled each day on the ascending and descending portions of the orbit. Within each 60-day window, least-squares fits are applied in order to extract the zonal mean, diurnal and semidiurnal solar (migrating and non-migrating) and lunar tides and stationary planetary waves. A data series of temperature residuals is obtained by subtracting these fits from the raw data.

Examples of raw temperature residuals (ascending data 

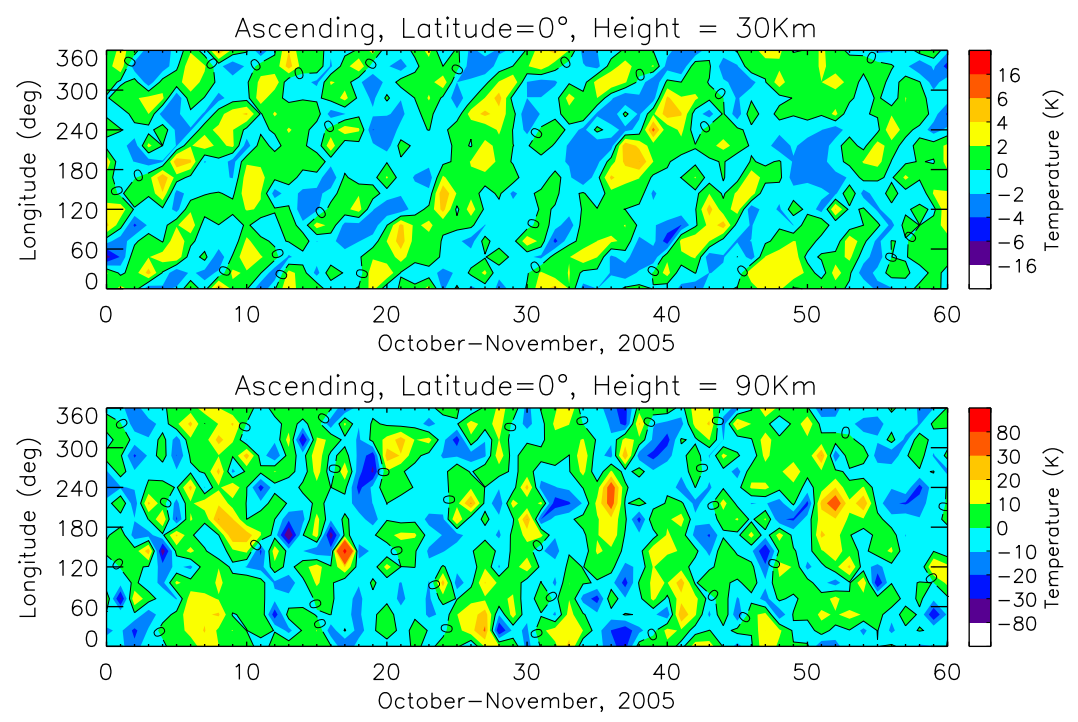

Fig. 1. Longitude versus time depiction of equatorial temperature residuals at $30 \mathrm{~km}$ (top) and $90 \mathrm{~km}$ (bottom) during October-November, 2005.

only) at $30 \mathrm{~km}$ and $90 \mathrm{~km}$ over the equator during October-November, 2005, are illustrated in Fig. 1. At $30 \mathrm{~km}$, eastward-propagating structures with periods of order 10 days with zonal wavenumbers $s=1$ and $s=2$ are readily seen, and very likely reflect the presence of Kelvin waves. However, at $90 \mathrm{~km}$ much larger temperature residual amplitudes exist, but no clear signatures of propagating structures are seen. At these altitudes, Kelvin waves are probably masked by temperature residuals associated with gravity waves, planetary waves and day-to-day variability of solar tides.

To determine the dominant equatorial oscillations, sliding fits to the temperature residuals were performed with the following constraints: zonal wavenumbers $s=-6$ (eastward) to $s=+6$ (westward); wave periods 2.0 to 20.0 days in increments of 0.5 days; window length $=3$ times the wave period; all available data during 2002-2006. For each wave period-zonal wavenumber combination, amplitudes for all years were averaged to obtain a multi-year mean spectrum at each height and latitude.

\section{Wavenumber-period Spectra}

A typical spectrum, corresponding to $86 \mathrm{~km}$ over the equator, is provided in Fig. 2(a). Note that significant "background energy" is embedded in the spectrum, reflecting the random-like residuals depicted in the bottom panel of Fig. 1. The associated "background spectrum" (Fig. 2(b)) is obtained by repeated 1-2-1 smoothing (80 iterations) of the original spectrum (Fig. 2(a)). This method is the same as that applied by Wheeler and Kiladis (1999) to outgoing longwave radiation (OLR) data in the tropics to reveal a variety of convectively-generated waves. Removal of the background spectrum from the original spectrum yields the multi-year spectrum in Fig. 2(c). This spectrum reveals several maxima that can plausibly be related to several waves familiar to most readers based upon their repeated appearance in the literature: The 6-7 days westward-propagating oscillation with $s=+1$; the $\sim 16$ day westward-propagating normal mode with $s=+1 ; 3.0-$
3.5 day ultra-fast Kelvin waves with $s=-1$, and $\sim 10$ day and $\sim 18$-day zonally symmetric $(s=0)$ oscillations that may be the high-frequency end of intra-seasonal oscillations (ISO) of the zonal mean state, possibly driven by Eliasssen-Palm Flux Divergences (EPFD) due to UFKW and diurnal tides (DT) associated with variable convection and latent heating in the tropical troposphere (Miyoshi and Fujiwara, 2006). We return to the question of wave driving of the ISO later in this paper.

Figure 3 provides the multi-year spectra in a different form, namely amplitudes as a function of height and period for zonal wavenumbers $s=-1$ and $s=-2$, i.e., eastwardpropagating waves. Background spectra have been removed in the same manner as in Fig. 2. However, note that since the background spectra were determined by repeated smoothing in the height-period plane in Fig. 3 but in the wavenumber-period plane in Fig. 4, that exact consistency between the two depictions is not obtained. For instance, Fig. 2 indicates that $s=-2$ waves at 2-day period do not penetrate above $90 \mathrm{~km}$, but this wave is evident at $104 \mathrm{~km}$ altitude in Fig. 4. Results very similar to those depicted in Fig. 3 were obtained by examining the component of temperature residuals between $\pm 50^{\circ}$ latitude that is symmetric about the equator. Also, no notable results were obtained when the antisymmetric component of the temperature residuals was examined in the same manner. Therefore, we conclude that the eastward propagating waves depicted in Figs. 2 and 3 are predominantly Kelvin waves (albeit possibly slightly distorted in shape with respect to latitude instead of being perfectly symmetric), and that Kelvin waves represent the dominant form of non-tidal wave motions characterizing the stratosphere and MLT dynamics at equatorial latitudes.

Also provided in this plot are vertical wavelengths $\left(\lambda_{z}\right)$ estimated from simple wave theory for Kelvin waves (Holton et al., 2001):

$$
\lambda_{z}=\frac{2 \pi}{N}\left(\frac{\lambda_{x}}{T}-\bar{u}\right)
$$


Altitude $=86 \mathrm{Km}$, Lat $=0^{\circ}$
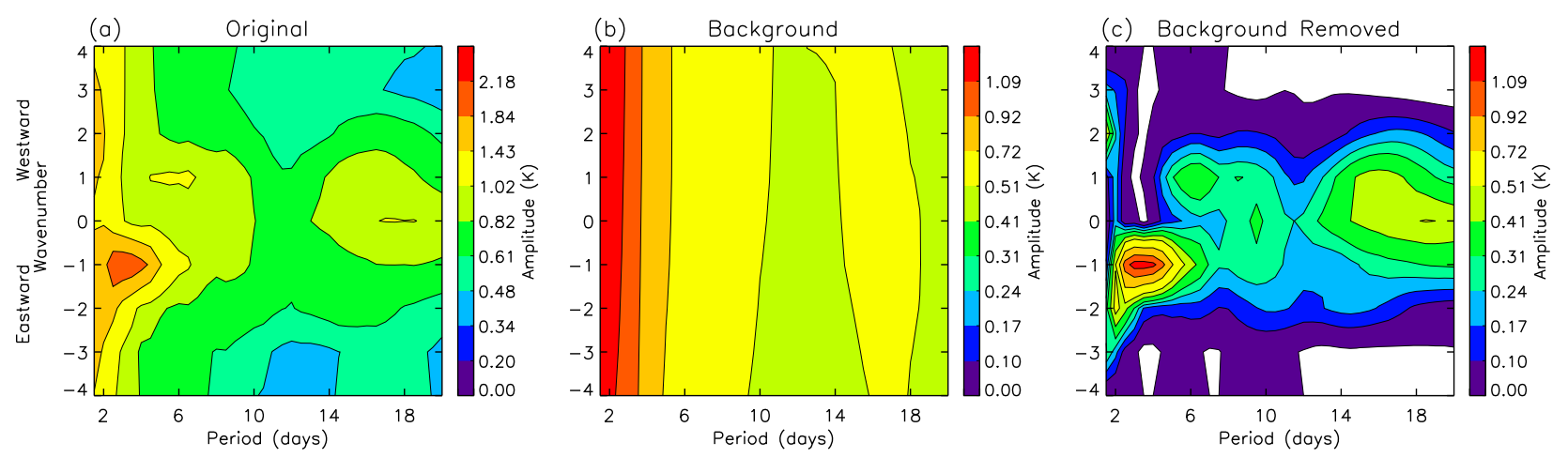

Fig. 2. (a) A typical wavenumber-period spectrum, in this case corresponding to $86 \mathrm{~km}$ over the equator, and averaged over 2002-2006. Note that significant "background energy" is embedded in the spectrum, reflecting the random-like residuals depicted in Fig. 1(b). The associated "background spectrum" (b) is obtained by repeated 1-2-1 smoothing of the original spectrum in (a). Removal of the background spectrum (b) from the original spectrum (a) yields the multi-year spectrum in panel (c).
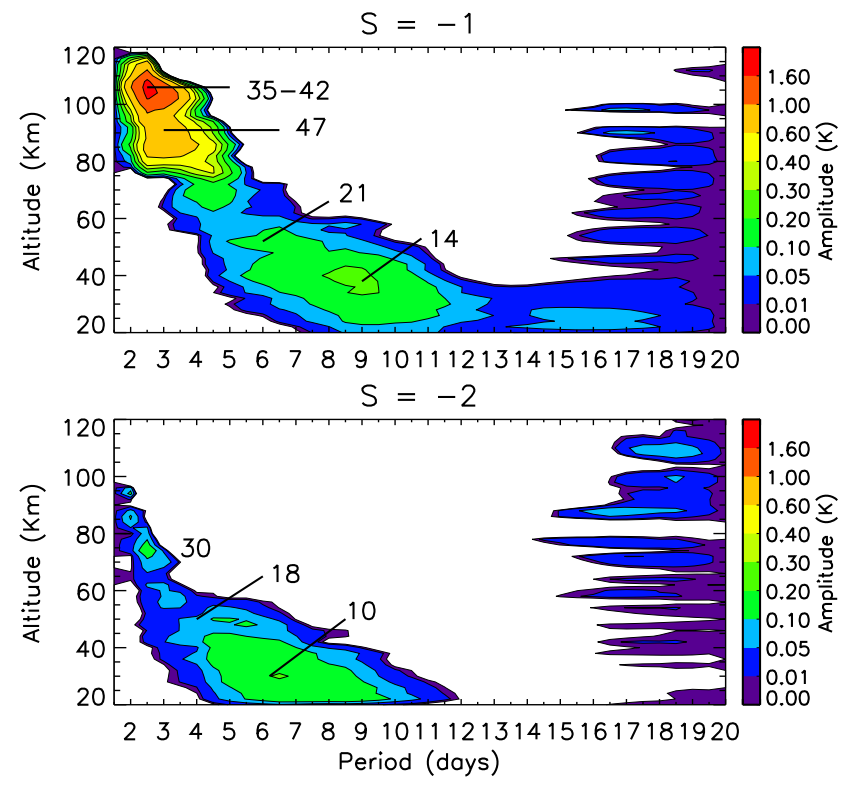

Fig. 3. Height versus period spectrum of eastward-propagating waves over the equator with zonal wavenumber $s=-1$ (top) and $s=-2$ (bottom). This spectrum represents an average over all data during 2002-2006. Vertical wavelengths calculated according to Eq. (1) are indicated.

where $\lambda_{x}=$ zonal wavelength, $T=$ wave period, $N=$ buoyancy frequency, and $\bar{u}=$ zonal mean zonal wind speed. We found $\lambda_{z}$ 's for $\bar{u}=0$ to differ only slightly from those where rough estimates of climatological values were used, so the displayed values reflect $\bar{u}=0$. Values for $N$ were derived from equatorial temperature profiles in the msise 90 empirical model (Hedin, 1991). The $s=-2$ oscillations near $20 \mathrm{~km}$ altitude have typical periods in the 5-10 day range with vertical wavelengths of order $10 \mathrm{~km}$; zonal phase speeds are of order $25-45 \mathrm{~m} \mathrm{~s}^{-1}$. Such short vertical wavelengths and slow phase speeds suggest that these waves will not propagate into the mesosphere due to potential dissipation and mean wind effects, at least during some seasons or cycles of the QBO.

By $75 \mathrm{~km}$ the predominant $s=-2$ waves have periods of about 2.5 days and vertical wavelengths of about $30 \mathrm{~km}$; however, no significant penetration into the MLT region (ca. $80-120 \mathrm{~km}$ ) is evident. One must bear in mind, however, that these spectra are averaged over all seasons and QBO phases covering several years. Thus, vertical penetration into the MLT by $s=-2$ Kelvin waves is not necessarily precluded under favorable conditions.

The dominant stratospheric waves for $s=-1$ occur in the 6-12 day period range with typical vertical wavelengths of order $14 \mathrm{~km}$, and phase speeds in the range $40-80 \mathrm{~m} \mathrm{~s}^{-1}$. Despite the reduced susceptibility to mean wind filtering, these "fast" Kelvin waves do not penetrate much above $60 \mathrm{~km}$. The predominant waves reaching the MLT are in the 2-4 day period range with vertical wavelengths of order $35-50 \mathrm{~km}$. This result is in accord with available groundbased measurements.

Figure 4 illustrates spectra similar to those in Fig. 2(c) at four different heights: $24 \mathrm{~km}, 54 \mathrm{~km}, 78 \mathrm{~km}$, and $104 \mathrm{~km}$. At $24 \mathrm{~km}$ the relation between zonal wavenumber and period is almost linear from $s=-4$ and 4 days to $s=-1$ and 9 days, with vertical wavelengths in the $9-12 \mathrm{~km}$ range. Kelvin waves with $s=-1$ occur for 9 days to 18 days period. At $54 \mathrm{~km}$, this linear relation between period and zonal wavenumber shifts towards shorter wavelengths, and vertical wavelengths increase to $14-21 \mathrm{~km}$. The long-period $s=-1$ Kelvin waves disappear, and the zonally-symmetric $(s=0)$ oscillation becomes evident at periods $>14$ days. A distinct peak also occurs for $s=+1$ (westward) at period $\approx 10$ days which corresponds to a well-known normal mode. This latter peak shifts to shorter periods (68 days) by $78 \mathrm{~km}$ and the zonally symmetric oscillation intensifies and also extends to lower periods ( $\sim 8$ days). The Kelvin wave spectrum also shifts to earlier periods $(2.5-$ 5.0 days) and longer vertical wavelengths $(30-40 \mathrm{~km})$. By $104 \mathrm{~km}$, the clearly predominant oscillation is the $s=-1$ UFKW near 2.5-day period with vertical wavelengths of order $35-42 \mathrm{~km}$. The only remaining wave components are the greatly diminished zonally symmetric oscillations at 10day and >18-day periods. 

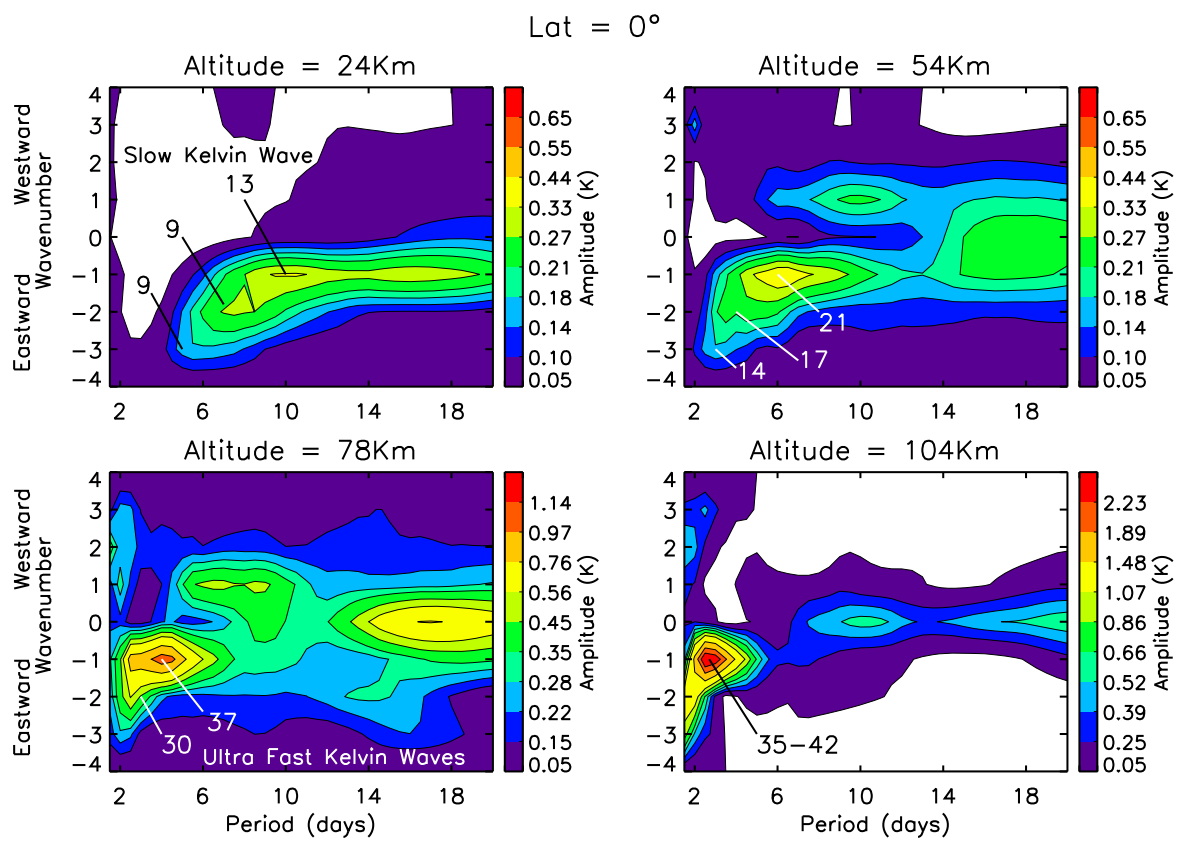

Fig. 4. Equatorial wavenumber versus period spectra at $24 \mathrm{~km}, 54 \mathrm{~km}, 78 \mathrm{~km}$, and $104 \mathrm{~km}$, averaged over 2002-2006, derived in the same manner as the example in Fig. 2. Vertical wavelengths calculated according to Eq. (1) are indicated.
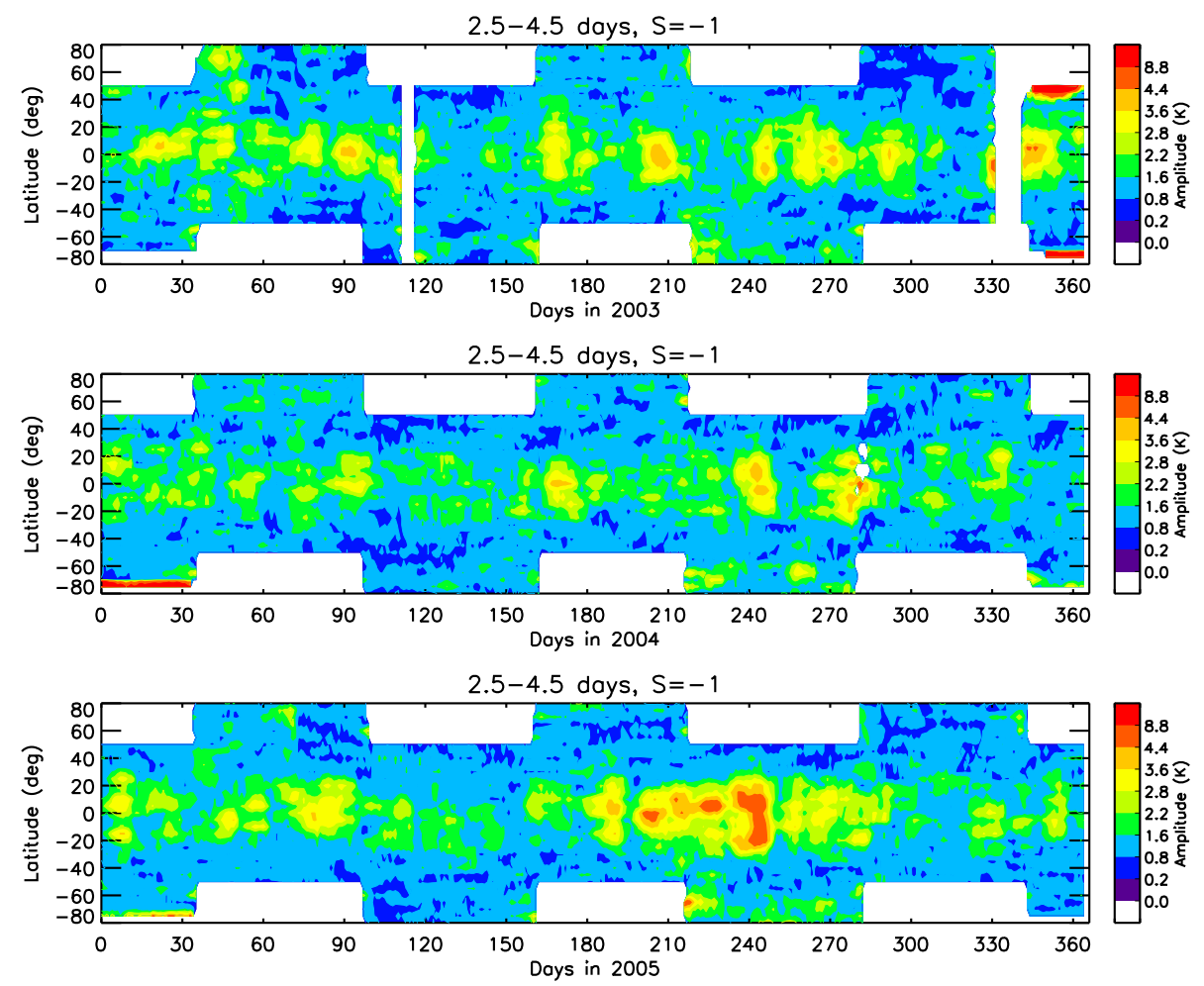

Fig. 5. Average amplitudes of eastward-propagating $s=-1$ waves within the 2.5-4.5-period band at $90 \mathrm{~km}$ during 2003 (top), 2004 (middle) and 2005 (bottom).

\section{UFKW and ISO in the MLT}

In the context of a full-atmosphere GCM, Miyoshi and Fujiwara (2006) established a connection between EliassenPalm Flux Divergences (EPFD) due to migrating and nonmigrating diurnal tides (DT) and UFKW, and 20-60 day Intra-Seasonal Oscillations (ISO) in zonal mean winds. The intra-seasonal variations in DT and UFKW in the MLT are connected with established troposphere ISO's at 20-25 days
(Hartmann et al., 1992) and 40-60 days (Madden and Julian, 1994) manifested in tropical convection, e.g., latent heating rates that force the DT and UFKW. Previous similar suggestions and supportive observations relating waves and ISO in the MLT are provided by Eckerman and Vincent (1994), Eckerman et al. (1997), Isoda et al. (2004), and Lieberman (1998). In this section we briefly consider the potential connections between UFKW variability 

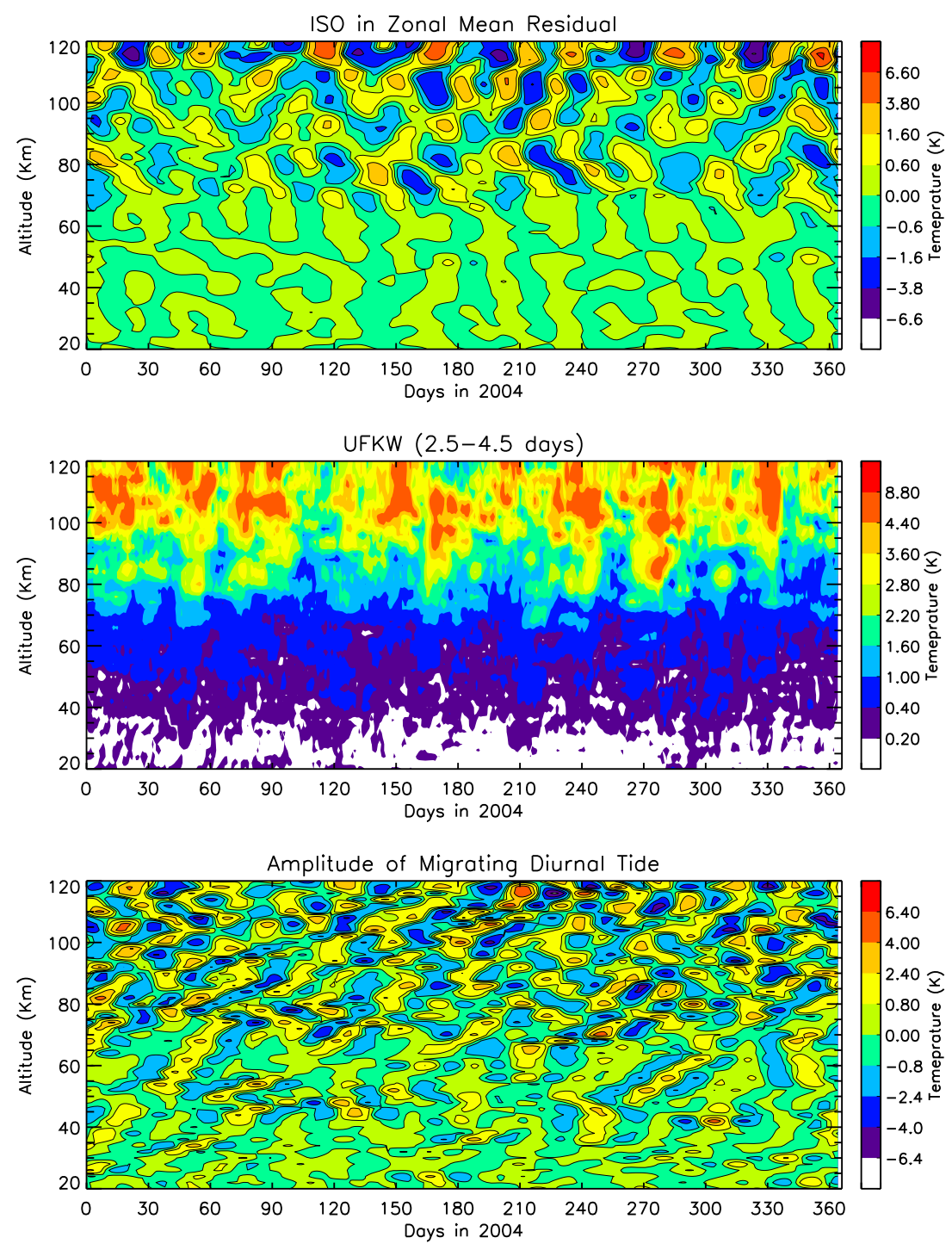

Fig. 6. Amplitudes of zonal mean residual temperatures (top), UFKW temperature amplitudes (middle), and migrating tide temperature amplitudes (bottom) during 2004, illustrating intra-seasonal variability in the 20-60 day period range.

and the ISO of the zonal mean state in the context of the TIMED/SABER temperature measurements.

Figure 5 illustrates the average temperature amplitudes of eastward-propagating waves with $s=-1$ and periods between 2.5 and 4.5 days (i.e., UFKW) at $90 \mathrm{~km}$ for 20032005. Note the quasi-symmetry about the equator as expected for Kelvin waves. The UFKW exists throughout the year, but amplitudes are characterized by intermittency and interannual variability. Since the UFKW are likely generated by latent heating associated with tropical convection, the observed UFKW intermittency is thought to originate from this source.

Figure 6(b) provides a height vs. time view of the UFKW amplitudes during 2004, and corresponds to the 2004 data illustrated at $90 \mathrm{~km}$ in Fig. 5(b). Figure 6(a) illustrates the daily zonal mean temperature residuals in the same format, filtered to include periods between 20-60 days, and Fig. 6(c) represents the corresponding DT temperature amplitude residuals. Note that both the UFKW amplitudes and residual zonal mean amplitudes are mainly confined to the $80-120 \mathrm{~km}$ height region. Variations in the zonal mean temperature residuals are generally of order $\pm 2-4 \mathrm{~K}$, and UFKW amplitude variability is generally in the range of 0 $8 \mathrm{~K}$. The question remains, are the variabilities depicted in Figs. 6(a), 6(b) and 6(c) related to each other?

To further quantify the variabilities seen in Fig. 6, in Fig. 7 we illustrate spectra of the UFKW and migrating DT amplitudes and the zonal mean temperature residuals at $80 \mathrm{~km}$ over the equator. The spectra illustrated in Fig. 7 represent the average of the spectra for the individual years 2003, 2004, and 2005. The DT results only include the migrating diurnal tide, and correspond to residuals from daily 60-day running mean values due to the local time sampling afforded by the slowly-precessing TIMED spacecraft; therefore, DT spectral amplitudes at periods less than about 30 days are strongly damped. Nevertheless, note that peaks appear in all three spectra near 20, 24, 26-27, 30-33, 3739 days, and between 50-60 days, suggesting some physical connection. Unfortunately, our attempts at representing the ISO time series as some empirical combination of the DT and UFKW time series in a least-squares regression analysis did not lead to any fits that captured a sig- 

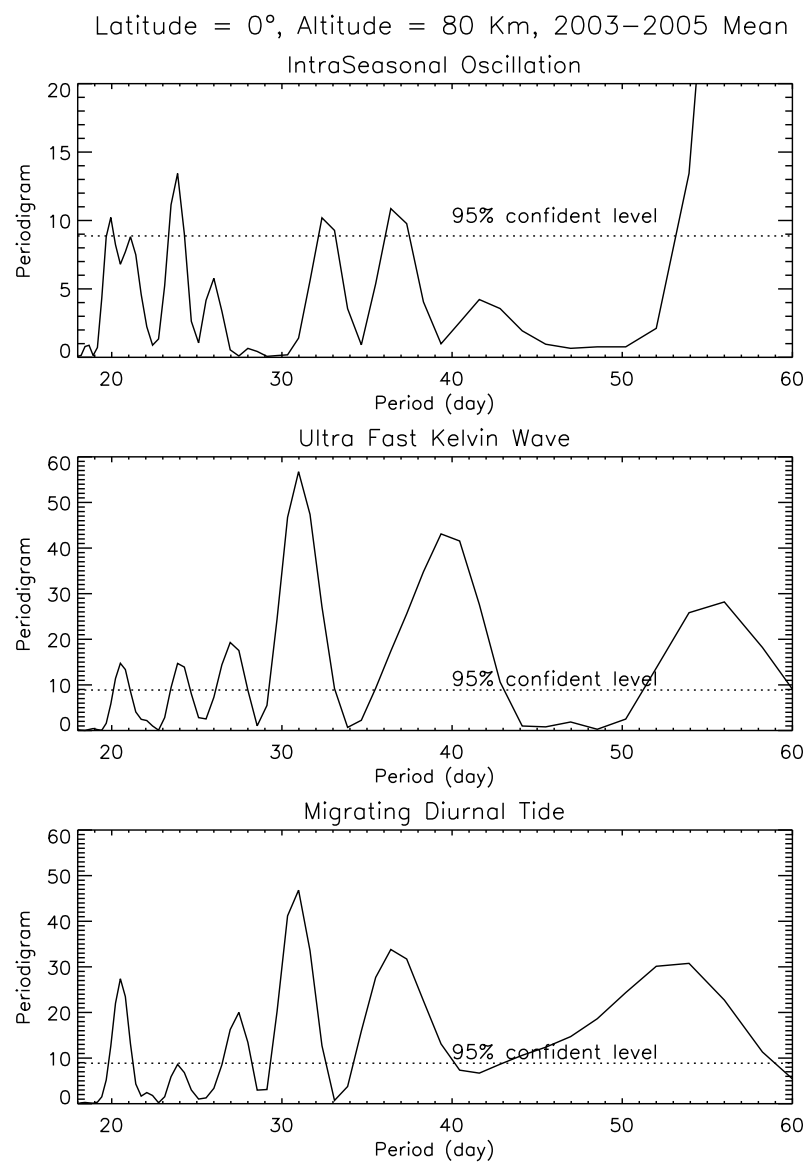

Fig. 7. Average spectra (covering 2003-2005) at $80 \mathrm{~km}$ over the equator for the zonal mean temperature residuals (top), UFKW (middle) and migrating DT (bottom), illustrating periods of intra-seasonal variability.

nificant fraction of the total variance; in other words, the ISO time series is not well correlated with either the DT or UFKW time series. One reason for this is that we have underestimated the migrating DT variability at periods less than about 30 days. Another is that the present results do not consider the additional influence of non-migrating tides, which apparently play a significant role in driving the ISO in the MLT (Miyoshi and Fujiwara, 2006). Thus, although the results in Fig. 7 are consistent with the concept that EPFD associated with UFKW and migrating DT variability may drive similar periodicities in the zonal mean state, our results do not constitute proof of such a connection. We consider that a more comprehensive analysis of the problem is out of the scope of the present paper, and must be reserved for future studies.

\section{Conclusions}

Our conclusions may be summarized as follows:

(1) SABER temperature data provide the first opportunity to "see" vertical coupling from the lower stratosphere to lower thermosphere in the equatorial region vis-à-vis vertically-propagating waves with periods $>2$ days.

(2) The dominant waves responsible for this coupling are symmetric eastward-propagating waves, i.e., Kelvin waves.
(3) Dominant Kelvin waves transition from long-periods (5-10 days) and short-wavelengths $(9-13 \mathrm{~km})$ in the stratosphere, to shorter periods (2-3 days) and longer wavelengths $(35-45 \mathrm{~km})$ in the MLT.

(4) UFKW (periods 2.5-4.5 days) intermittently exist at similar amplitudes $(3-10 \mathrm{~K}, 80-120 \mathrm{~km})$ during all months of the year, with variability in the 20-60 day range.

(5) An ISO of zonal mean temperatures also exists with periods 20-60 days that may be driven by EPFD due, at least in part, to UFKW and migrating diurnal tides.

(6) The zonal mean ISO preferentially exists above $70 \mathrm{~km}$, consistent with in-situ generation at these altitudes.

(7) A more definitive analysis of wave generation of the ISO requires consideration of the full spectrum of migrating and non-migrating tides, and application of methodologies (i.e., ascending minus descending node analyses) that provide a quantitative measure of dayto-day variability at periods less than 30 days. This work is ongoing, and will be reported on in the future.

Acknowledgments. This work was supported by the NASA TIMED Program under grants NAG5-5028 and NNX07AB74G to the University of Colorado.

\section{References}

Canziani, P. O., J. R. Holton, E. Fishbein, and L. Froidevaux, Equatorial Kelvin wave variability during 1992 and 1993, J. Geophys. Res., 100 5193-5202, 1995.

Eckermann, S. D. and R. A. Vincent, First observations of intraseasonal oscillations in the equatorial mesosphere and lower thermosphere, Geophys. Res. Lett., 21, 265-268, 1994.

Eckermann, S. D., D. K. Rajopadhyaya, and R. A. Vincent, Intraseasonal wind variability in the equatorial mesosphere and lower thermosphere: Long term observations from the central Pacific, J. Atmos. Sol. Terr. Phys., 59, 603-627, 1997.

Hartmann, D. L., M. I. Michelson, and S. A. Klein, Seasonal variations of tropical intraseasonal oscillations: A 20-25-day oscillation in the western Pacific, J. Atmos. Sci., 49, 1277-1289, 1992.

Hedin, A. E., Extension of the thermosphere model into the middle and lower atmosphere, J. Geophys. Res., 96, 1159-1172, 1991.

Hirota, I., Kelvin waves in the equatorial middle atmosphere observed by the Nimbus 5 SCR, J. Atmos. Sci., 36, 217-222, 1979.

Holton, J. R., M. Joan Alexander, and M. T. Boehm, Evidence for short vertical wavelength Kelvin waves in the Department of EnergyAtmospheric Radiation Measurement Nauru99 radiosonde data, J. Geophys. Res., 106, 20125-20130, 2001.

Isoda, F., T. Tsuda, T. Nakamura, R. A. Vincent, I. M. Reid, E. Achmad, A. Sadewo, and A. Nuryanto, Intraseasonal oscillations of the zonal wind near the mesopause observed with medium-frequency and meteor radar in the tropics, J. Geophys. Res., 109, D21108, doi:10.1029/2003JD003378, 2004.

Liebermann, R. S., Intraseasonal variability of high resolution Doppler imager winds in the equatorial mesosphere and lower thermosphere, $J$. Geophys. Res., 103, 11,221-11,228, 1998.

Liebermann, R. S. and D. Riggin, High resolution Doppler Imager observations of Kelvin waves in the equatorial mesosphere and lower thermosphere, J. Geophys. Res., 102, 26,117-26,130, 1997.

Madden, R. A. and P. R. Julian, Observations of the 40-50 day tropical oscillation-A review, Mon. Weather Rev., 122, 814-837, 1994.

Maruyama, T., Upward transport of westerly momentum due to large scale disturbances in the equatorial lower stratosphere, J. Meteor. Soc. Jpn., 47, 245-254, 1968.

Miyoshi, Y. and H. Fujiwara, Excitation mechanism of intraseasonal oscillation in the equatorial mesosphere and lower thermosphere, J. Geophys. Res., 111, D14108, doi:10.1029/2005JD006993, 2006.

Mote, P. W., T. J. Dunkerton, and Wu Dong, Kelvin waves in stratospheric temperature observed by the Microwave Limb Sounder, J. Geophys. Res., 107(D14), 4218-4229, doi:10.1029/2001JD001056, 2002. 
Randel, W. J. and F. Wu, Kelvin wave variability near the equatorial tropopause observed in GPS radio occultation measurements, $J$. Geosphys. Res., 110, D03102, doi:10.1029/2004JD005006, 2005.

Riggin, D. M., D. C. Fritts, T. Tsuda, T. Nakamura, and R. A. Vincent, Radar observations of a 3-day Kelvin wave in the equatorial mesosphere, J. Geophys. Res., 102, 26,141-26,157, 1997.

Salby, M. L. and R. R. Garcia, Transient response to localized epidemic heating in the tropics Part 1, J. Atmos. Sci., 44, 458-497, 1987.

Salby, M. L., D. L. Hartmann, P. L. Bailey, and J. C. Gille, Evidence for equatorial Kelvin modes in Nimbus-7 LIMS, J. Atmos. Sci., 41, 220235, 1984.

Tsai, H.-F., T. Tsuda, G. A. Hajj, J. Wickert, and Y. Aoyama, Equatorial Kelvin waves observed with GPS occultation measurements (CHAMP and SAC-C), J. Meteor. Soc. Jpn., 82, 397-406, 2004.

Vincent, R. A., Long-period motions in the equatorial mesosphere, J. Atmos. Terr. Phys., 55, 1067-1080, 1993.
Wallace, J. M. and V. E. Kousky, Observational evidence of kelvin waves in the tropical stratosphere, J. Atmos. Sci., 25, 900-907, 1968.

Wheeler, M. and G. N. Kiladis, Convectively coupled equatorial waves: Analysis of clouds and temperature in the wavenumber-frequency domain, J. Atmos. Sci., 56, 374-399, 1999.

Yoshida, S., T. Tsuda, A. Shimizu, and T. Nakamura, Seasonal variations of 3.0-3.8 day ultra-fast Kelvin waves observed with a meteor wind radar and radiosonde in Indonesia, Earth Planets Space, 51, 675-684, 1999.

J. M. Forbes (e-mail: forbes@colorado.edu), X. Zhang, S. E. Palo, J. Russell, C. J. Mertens, and M. Mlynczak 